\title{
Improvements in Movement of Empty Containers: The Case of the Port of Gothenburg
}

\author{
Violeta Roso \\ Department of Technology Management and Economics, \\ Division of Logistics and Transportation, Chalmers University of Technology, \\ 41296 Gothenburg, Sweden \\ Email: violeta.roso@ chalmers.se (Corresponding Author) \\ Nils Andersson \\ Department of Technology Management and Economics, \\ Division of Logistics and Transportation, Chalmers University of Technology, \\ 41296 Gothenburg, Sweden \\ Email: nils.andersson@chalmers.se \\ Joakim Widstrand \\ Department of Technology Management and Economics, \\ Division of Logistics and Transportation, Chalmers University of Technology, \\ 41296 Gothenburg, Sweden \\ Email: joakim.widstrand@chalmers.se \\ Kent Lumsden \\ Department of Technology Management and Economics, \\ Division of Logistics and Transportation, Chalmers University of Technology, \\ 41296 Gothenburg, Sweden \\ Email: kent.lumsden@chalmers.se
}

\begin{abstract}
Capacity increase only at seaport facilities without improvements in seaports' inland access is not enough for the entire container transport chain to function properly. With constantly growing container transports, efficiency of rail and flexibility of road are increasingly needed for inland access to/from the seaports, however not always sufficient. Therefore the purpose of this study is to compare movement of empty containers by barge and long and heavy vehicles (LHV) to the reference situation done by regular trucks, on the case of port of Gothenburg and one of its nearby depots; with regard to economy, environment, flexibility and time efficiency. Currently the transportation of containers between the container terminal in the port of Gothenburg and the container depot located $6,5 \mathrm{~km}$ at Risholmen is carried out by trucks of a maximum capacity of three TEUs. The data for the study were collected through interviews, observation and literature review. The literature in general claims that barge is a very cost efficient and low polluting mode of transportation but in which circumstances? The findings of the study are focusing on how the studied modes are performing with respect to suggested criteria and show LHV to be the most suitable mode of transport for given route. Not only that the proper choice of the mode has an economic effect, but it also has an environmental impact due to reduced fuel consumption resulting in lower emissions.
\end{abstract}

Keywords: barge, LHV, empty containers, depot, Port of Gothenburg

\section{INTRODUCTION}

Maritime transportation is a steadily growing global industry. To adapt to this growth, ports strive to stay competitive by offering competitive port and hinterland services (Alderton, 2008). Since majority of the ports are located in densely populated areas, expansion within the port area is difficult and this has put challenges on ports to increase the efficiency in port activities and in the land use, to be able to efficiently handle the increased volumes (Roso et al, 2009b). The phenomenon of containerisation has facilitated the handling and increased the security of goods and products, which are the keystones for the global production and trade. However repositioning of empty containers is considered to be one of the biggest issues in the shipping industry. An increasing number of containers are repositioned empty because it is hard to find a cargo for a return leg. Not only that it has an economic effect, but it also has an environmental impact, since the reduction of empty container movements should reduce fuel consumption as well as congestion and emissions (Song and Carter, 2009). Container depots are often required to support the shipping lines' activities, for instance with storing and reparation of containers, consolidation of goods and similar activities, and movement of empties between different depots/terminals and the seaport is a part of the problematic repositioning management. Positioning of inland terminals and their 
possibility for expansion is of high significance for sustainable development (Brnjac and Cavar, 2009). With constantly growing container transports, efficiency of rail and flexibility of road are increasingly needed for inland access to/from the seaports (Frémont and Franc, 2011), however not always sufficient. Recently sustainability has received increasing attention and with it also the role that logistics concepts can play in making transport more sustainable. Improvements like, for example, the implementation of Longer and Heavier Vehicles (LHV), would contribute to sustainability of road transport Åkrman and Jonsson (2007). According to McKinnon (2005) an increase in maximum truck weight from 41 tonnes to 44 tonnes would have the effect of reducing road haulage costs per tonne-km for weight-constrained loads by roughly $11 \%$. Wiegmans and Konings (2007) and Lowe (2005) claim that transportation by barge, apart for having good transport economy, is also the safest mode of transportation. The arguments are based on the low number of accidents with practically no fatalities, probably due to slow speed of the vessel in combination with low traffic density. Therefore the purpose of this study is to compare movement of empty containers by regular truck, as it is done today, and by barge and LHV on the case of port of Gothenburg and one of its nearby depots; with regard to economy, environment, flexibility and time efficiency. The transportation of containers between the container terminal at the port of Gothenburg and the container depot located approximately $6.5 \mathrm{~km}$ at Risholmen is carried out with trucks with a maximum capacity of three TEUs, today.

\section{RESEARCH APPROACH}

An advantage of the case study method is that the case is studied in its real environment, which makes it possible to obtain a well-developed understanding and knowledge for the studied area (Flyvbjerg, 2006). Furthermore, in order to ensure validity, triangulation with multiple means of data collection can be conducted. However, a single case does not allow a generalization (ibid). Data for the cases has been collected primarily through face-to-face and phone interviews and literature reviews, combined with site visits. In addition, a number of secondary sources were used, such as reports and internal documents. The interviews have been in between open and structured type of interviews and all interviews have, after permission from the respondent, been recorded with the length varying from 30 min to 1 hour. The rationale for using this interview technique was based on the fact that the subject and the areas, which were of interest, were well predefined. Some parts of the interviews are of the well-structured type since the data needed was of strict quantitative form such as for example information about costs. And, the fact that data related to the cost is of a sensitive character the same have not been disclosed in this paper in detail. The interviewees have a wide span of backgrounds, from truck drivers to CEOs, since the authors wanted to cover as many perspectives of the container flow as possible. The interviewees' organizations and positions are summarized in Table $\mathbf{1}$ below.

Table 1 Interviewees' Organizations, Their Positions and the Type of the Interview

\begin{tabular}{|l|l|l|}
\hline Organization & Interviewees' Position & Interview type \\
\hline APM Terminals & Process developer & Face to face \\
\hline APM Terminals & Head Security Environment Officer & Face to face, e-mail \\
\hline APM Terminals & Port Operator & Phone \\
\hline BA Consulting AB & Senior Advisor/ Marine Director & Face to face, phone, e-mail \\
\hline Chalmers University & Professor & Face to face \\
\hline CMA CGM & Container Manager & Phone \\
\hline ContainerCare AB & Administration and Gate & Face to face \\
\hline ContainerCare AB & Area Manager & Phone \\
\hline Equest AB & Environmental Consultant & Phone \\
\hline European Barge Union & Secretary General & Phone \\
\hline European Barge Union & Chair Member & Phone \\
\hline GCT AB & Area Manager/ Market & Face to face \\
\hline GCT AB & Responsible of Depot & Phone, e-mail \\
\hline Inland Navigation Europe & Office Manager & Phone, e-mail \\
\hline Konecranes & Sales Division & Phone \\
\hline Mercurius Shipping Group & Employee & E-mail \\
\hline NCC Roads AB & Sales and Marketing & Phone \\
\hline Port of Gothenburg & Development and Sustainability & Face to face \\
\hline Port of Gothenburg & Port Captain & Face to face \\
\hline RPG Group & CEO & Face to face \\
\hline
\end{tabular}


Table 2 Interviewees' Organizations, Their Positions and the Type of the Interview (Con't)

\begin{tabular}{|l|l|l|}
\hline RPG Group & Truck driver & Phone \\
\hline RPG Group & Truck driver & Phone \\
\hline Sandinge B och S & Owner & Phone \\
\hline Skaraslättens Transport AB & Area Manager/ Traffic Responsible & Phone \\
\hline Wåhlemans Transport AB & Truck driver & Phone \\
\hline
\end{tabular}

Observations can have participative or nonparticipative form (Björklund \& Paulsson, 2007). The nonparticipative observation carried out here had the purpose to measure the container capacity utilisation of the trucks transporting containers between the depots at Risholmen and the container terminal in order to for example use the values when calculating the environmental impact from the trucks. The employees at the companies at Risholmen, CCAB and GCTAB, where interviewed and asked about those figures but in order to put extra validity to the given values, the observations were performed. The observations involved counting the trucks leaving Risholmen and entering the depot at the terminal in order to identify the trucks that had travelled between the two sites. This was necessary since all trucks leaving Risholmen or the depot do not end up at one of these locations. Network for Transport and Environment (NTM) has been used for environmental performance calculations. With this method, freight transport systems performances could be calculated by use of a specific NTM document (NTM, 2007).

\section{FRAME OF REFERENCE}

\subsection{Regular Truck}

The European Union has common legislation when it comes to size and weight limitations for vehicles operating between the member states. However, Sweden and Finland have an exception from these rules due to the long distances that have to be covered in these countries as well as due to the fact that prior to their entry into the EU, both countries regulations allowed considerably longer vehicles than the rest of Europe. The rest of the EU has a maximum allowed length and weight of $18.75 \mathrm{~m}$ and 40 tonnes, but it is up to the individual member states to set the limits for domestic traffic ( $\mathrm{k}$ krman and Jonsson, 2007). In 1997, an annexe was made to allow vehicle combinations of $25.25 \mathrm{~m}$ and 60 tonnes if the vehicles were built from the European Modular System (EMS) (ibid) and the same is in use in Sweden and Finland now. The EMS is built up from modules that can be transported in the rest of the EU but also can be efficiently combined into combinations of $25.25 \mathrm{~m}$ for the markets with longer vehicles. The idea is that three European vehicle combinations can be rearranged into two combinations for transport in Sweden and Finland (see Figure 1).

Regarding the economy of the regular truck transportation, the majority of the costs, between 70 and $90 \%$, are variable and the rest are fixed (Bardi et al., 2006). The main parts of the cost are driver wages, equipment rents, fuel, depreciation of vehicle and insurances. The profit margins for truck transportation are in comparison to other modes of transport relatively low, a typical margin could be about $5 \%$ of the revenues (Bardi et al., 2006). The small margins are due to tough competition in the industry caused by the small entry barriers, which has created a large amount of variety of hauliers (Berwick \& Dooley, 1997). It is estimated that the energy consumption of road transportation is approximately $80 \%$ of the total energy consumption caused by transportation in Europe today (European Environmental Agency, 2009). Since a vast majority of the energy is fossil, the $\mathrm{CO} 2$-emissions are related to the energy consumption. Concerning the NOx-emissions, road transportation is estimated to be accountable for $40 \%$ of the total NOx-emissions caused by transportation (ibid). Road transport is considered as the most flexible mode of transportation, due to the possibilities to change the capacity of the truck relatively easy as well as the route which could be of importance if the demand of a product is changed or if accidents occur on the way.

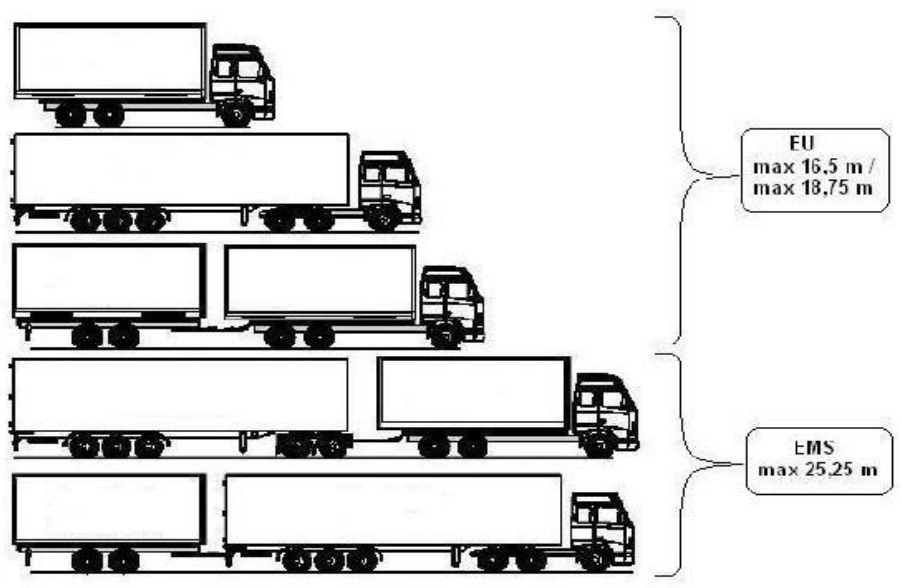

Figure 1 Differences Between EU-Maximum and EMSMaximum (Åkerman \& Jonsson, 2007)

\subsection{Longer and Heavier Vehicles}

Although LHV could generate certain economic and environmental benefits, a wider use of the concept is in debate in Europe due to safety issues (Åkrman and Jonsson, 2007). LHV are vehicles loaded with combinations of load carriers with a total length exceeding $25,25 \mathrm{~m}$; allowing transport of four, five or six TEUs at once. These transports are allowed in Sweden but only on certain roads, for instance on some roads in the port of Gothenburg area, which are jointly owned by the port of Gothenburg and Volvo (Roso et al, 2009a).

Regarding the economy of the LHV, the cost drivers are similar to the costs of regular trucks. However, since the capacity of the same transport link is increased between 33 and $100 \%$ depending on the size of the vehicle, the average costs are spread out on more TEUs. Depending on the depreciation time and the degree of utilisation of the trucks, the LHV scenario could lose some of its competitiveness due to the fact that some trucks for LHV transportation could be more than twice the price of a regular truck (Roso 
et al, 2009a). The increased variable costs due to a heavier loaded vehicle are relatively small; the fuel consumption for a fully loaded vehicle is approximately 4.5 and 5.5 litres per 10 kilometres for a regular truck and LHV respectively (ibid). The congestion on roads and the air pollution caused by LHV are lower per transported TEU than for regular truck transportation (Åkrman and Jonsson, 2007). The flexibility of the LHV may be inferior to the regular truck with the risk for lower capacity utilization however the possibility to consolidate different orders from different shipping companies is a mean for reducing the risk of postponement or low capacity utilization (Rakic \& Stegeman, 2011). Time efficiency is similar to regular trucks although with the limitations since LHV are allowed only on some privately owned roads (Roso et al, 2009a).

\subsection{Barge}

Many individual European Union member states and the European Commission see great potential in inland waterways with the purpose to reduce the freight transport on Europe's overcrowded road networks (Lowe, 2005). There are specific EU regulations regarding vessels transporting goods on inland waterways across Europe. These regulations specify a wide range of rules and technical requirements a vessel must follow as well as the restrictions and limitations of the intended waterways, for the vessel to be able to benefit from the advantages from inland waterways. The main advantages with inland waterways transportation compared to ocean transportation are the requirements of less crew and lower port and fairway charges as well as lower insurance costs. An inland waterway vessel may at the most be exposed to waves of two metres, the maximum load is 200 containers or 4000 tonnes of cargo, with a crew of two or three (ibid). The rules of inland waterways are not yet present in Sweden, however the same are under consideration.

The main advantage of barge is the good transport economy (Konings, 2003). The author claims that with an improved circulation time, the costs per item transported will decrease and vice versa. The vessel size of the barge affects the scale of operations on the barge system and an increased scale of operations may reduce the share of fixed and variable costs per transported item, depending on the fill rate of the vessel. Since the cost structure of the barge transport is mostly affected by the fixed costs, a reduction in the fill rate will have very small impact on the costs but a significant impact on the revenues. Here the fill rate for break-even is set to $75 \%$; consequently it is recommended to use suitable size of the vessel for a given volume (Lowe, 2005). Barge is considered as energy efficient mode with environmental advantages in comparison to road transportation. However, there are still emissions causing a significant environmental impact such as $\mathrm{CO} 2, \mathrm{NOx}$ and SOx. The high amount of SOx-emissions is specific to maritime transportation due to larger amount of sulphur in fuel used (European Environmental Agency, 2009). Although the flexibility of barge is poor, as for all water- based modes of transport, there are factors such as frequency of departures that could be adjusted in order to increase flexibility (Wiegmans \& Konings, 2007). However, since door-to-door transport is not possible by barge, a final leg is usually done by road requiring an extra transhipment. The time efficiency of barge transportation could be viewed as good since the arrival times often are according to schedule due to lower traffic density on the waterways compared to the roads. However since the speed of barge is considerably lower than for example for road transports, the transportation time may be longer, hence better planning of the transportation tasks is required.

\section{THE CASE DESCRIPTION}

\subsection{Port of Geothenburg}

The Port of Gothenburg is the largest container seaport in Scandinavia, handling more than 900,000 TEUs in 2012; with almost $30 \%$ of Swedish foreign trade passing through the port, it offers a wide range of routes, with traffic to over 140 destinations throughout the world (Port of Gothenburg, 2013). The rail terminal receives about 70 trains per day from inland destinations throughout Sweden and is considered to be the most trafficked goods-rail track in the country. Today, about $40 \%$ of all containers are transported by rail to inland destinations, and there are 24 rail shuttles for different destinations that run daily services from/to the port (Port of Gothenburg, 2013). Due to shortage of space the port had to place container depot on two locations; one depot shown as number 1-2-3-4 on Risholmen, which is a peninsula at the harbour entrance, about $6,5 \mathrm{~km}$ far from the main container terminal, indicated as number 7 in the Figure 2.

Several actors such as the port of Gothenburg, container handling companies, hauliers, shipping companies and terminal operators are involved in the empty container flow from Risholmen to the container depot at the container terminal. There are two companies operating at Risholmen which are involved in the container flow, these are GCT Container Depå AB (GCTAB as number 2) and Container Care $\mathrm{AB}$ (CCAB as number 3). Nordic Construction Company $\mathrm{AB}$ (NCC), indicated as number 1, uses the area as storage for sand and other kinds of construction materials. The black full line starting at Risholmen at 4 and ending at 7 is the route that regular trucks use to transport containers of maximum three TEUs between the two locations; this route is approximately $7,3 \mathrm{~km}$ long. The transportation by LHV, carrying four to six TEUs, takes the route from 4 to 7 however via dotted line between 5 and 6 in order to avoid the land which is classified as a Natura 2000 area inhabited by some 20 rare bird species (Naturvårdsverket, 2012). That route is about $6,5 \mathrm{~km}$ long and allows lower speed in general than the regular truck route. The white line, from 1 to 8 , would represent the barge route! 


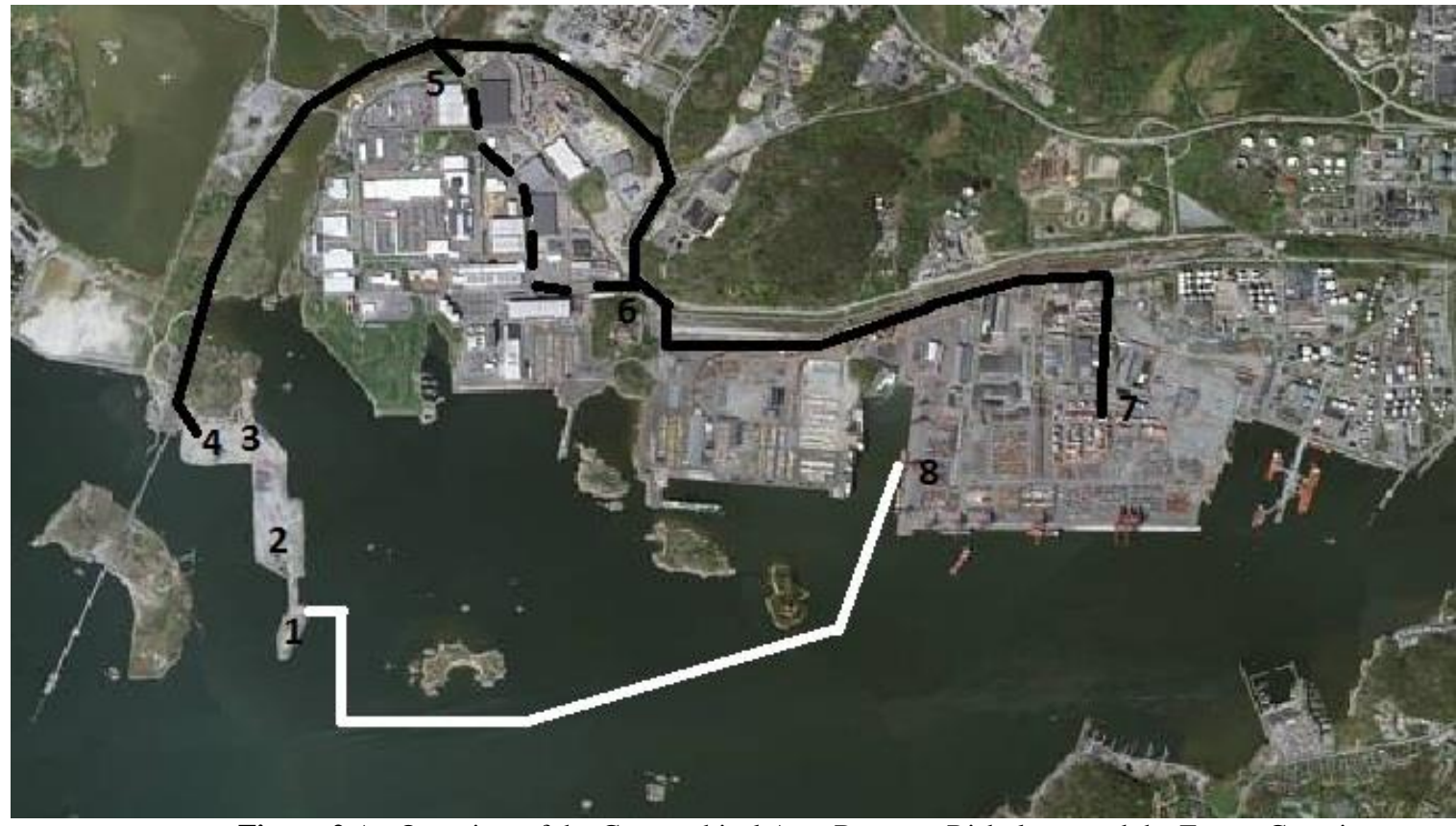

Figure 2 An Overview of the Geographical Area Between Risholmen and the Empty Container Depot and the Routes Studied in the Case

\subsection{Reference Situation with Regular Trucks}

The transportation of empty containers between Risholmen and the container terminal are initiated by the owners, which in most cases are the shipping companies. When a shipping company has decided to move a container from Risholmen to the container depot in the terminal, they normally start the process with ordering transportation from a haulage company. Thereafter, the shipping company contacts the involved actor at Risholmen. The company at Risholmen can receive this order few weeks in advance but also on a very short notice of few hours. When a truck arrives to pick up a container at Risholmen, the truck driver gives an order to an operator who tracks the container and delivers it with a reach stacker and places it on the truck. This process normally takes around 15 to 20 minutes and if there is a queue it might take longer. The regular truck route has a speed limit of $30 \mathrm{~km} / \mathrm{h}$ on some parts, however Gunnmalm (2009) report shows that $60 \%$ of the vehicles drive above $60 \mathrm{~km} / \mathrm{h}$ and that only $4 \%$ follows the speed restrictions. Furthermore, the road is perceived as safe and of good quality according to several truck drivers with long experience. Before entering the container terminal area, the trucks need to show their orders to the security on the gate 3 and this part of the journey is the most time consuming part due to the queues and normally takes between 45 and 90 minutes. Upon entering the gate 3 , the containers are lifted from the trucks by reach stackers that place them at the storage area. The whole process usually takes about 1 hour apart from rush hour times ( $4 \mathrm{pm})$ when it might extend to 2 hours. The cost for transportation on the route differs among the actors and varies between 175 and 250 sek per single container. The capacity utilisation on the route is estimated to be around $70 \%$ for the transportation in both directions.

\subsection{LHV Scenario}

The procedure followed by regular trucks for the transport of containers from 4 to 7 is the same for LHV with slightly different route as shown on the Figure 1. Special permission has been given to the haulage company RPG group to drive LHVs on that route and the price for a transport between the depot and the terminal is 250 SEK per container.

\subsection{Barge Scenario}

The maritime fairway from Risholmen to the container terminal is considered free of ice during the whole year and is approximately $2,4 \mathrm{~km}$ long. The quay at Risholmen, owned by NCC, is dredged to a maximum draft of $6,5 \mathrm{~m}$ and the other shores of Risholmen have an approximate draft of minimum $3 \mathrm{~m}$. The route has no speed limit except the entrance part of the terminal inlet where the speed limit is 8 knots. The quay is approximately $50 \mathrm{~m}$ long and $10 \mathrm{~m}$ wide and currently supporting vessels unloading materials at Risholmen on behalf of NCC. Unloading of material is carried out approximately twelve times a year by NCC, hence the utilisation rate is rather low. The western quay of the main container terminal is more appropriate for a barge, equipped with smaller ship-to-shore gantry cranes and a ramp which enables RoRo operations if necessary.

Procedure with self-propelled barge would be following. The advanced reach stacker lifts and transports containers from the storage site at Risholmen towards the barge at the quay and places the containers directly on the barge, the process repeats until all designated containers are positioned on the barge. Thereafter, the barge heads towards the western quay at the container terminal where they are unloaded to the shore by a gantry crane and picked up by a straddle carrier which transports the containers from the shore/quay to the entrance of the empty container depot where a reach stacker lifts the containers and places them on the designated storage site.

\section{ANALYSIS}

The analysis compares and evaluates the different modes of transportation for transport of 80 TEUs a day for 250 working days a year. As previously mentioned in the 
method section, data related to the cost is of sensitive character and therefore detailed calculations can not be disclosed.

\subsection{Economy}

The yearly cost for the reference situation with regular trucks is calculated to approximately 3,5 MSEK; when including the lifting costs from the truck to the storage space at the container terminal the total annual cost is approximately 3,8 MSEK.

In the LHV scenario the price is set 250 sek per container, regardless of the size; therefore the total annual cost is approximately 3,0 MSEK and with the charges in the port approximately 3,2 MSEK.

However, to make a proper and fair comparison between the two scenarios a shared price and cost structure has to be arranged. Since the costs for every transported item in truck transportation is more or less scale dependent, the difference in cost may be greater if a more fair comparison is made where economy of scale is taken in consideration. The marginal cost for transporting one more TEU compared to regular truck transportation is small since the machinery could be the same, however more trailers could be demanded and the labour cost could slightly increase. For this comparison to be completed, an equivalent price per transport occasion is adopted for both truck scenarios. The method is based on finding an average transport price per transport occasion for the regular truck proceeded with adapting this price per LHV scenario. This price is set to 330 SEK per transport occasion. If this price is increased with $10 \%$ for compensating for increased investments in container trailers for LHV, the total cost will amount to 1,5 MSEK for six TEUs transportation including the terminal charges and 2,1 MSEK for four TEUs transportation. This implies $100 \%$ capacity utilisation in the case of consolidation of containers, which is feasible. The results show clear benefits of using LHV, see Figure 3.

When comparing the different road scenarios and the self-propelled barge scenario, the road advantages are obvious for this short route (Figure 2). Since the barge scenario is associated with some heavy investments and higher port charges than the truck scenarios the total costs are higher. As previously presented the annual cost for this barge scenario is approximately 5,3 MSEK, including operation costs for barge and reach stacker as well as port cost for handling of the containers. Costs for starting up the barge line (currently non existing) with other implementation costs, administrative or similar, are not included.

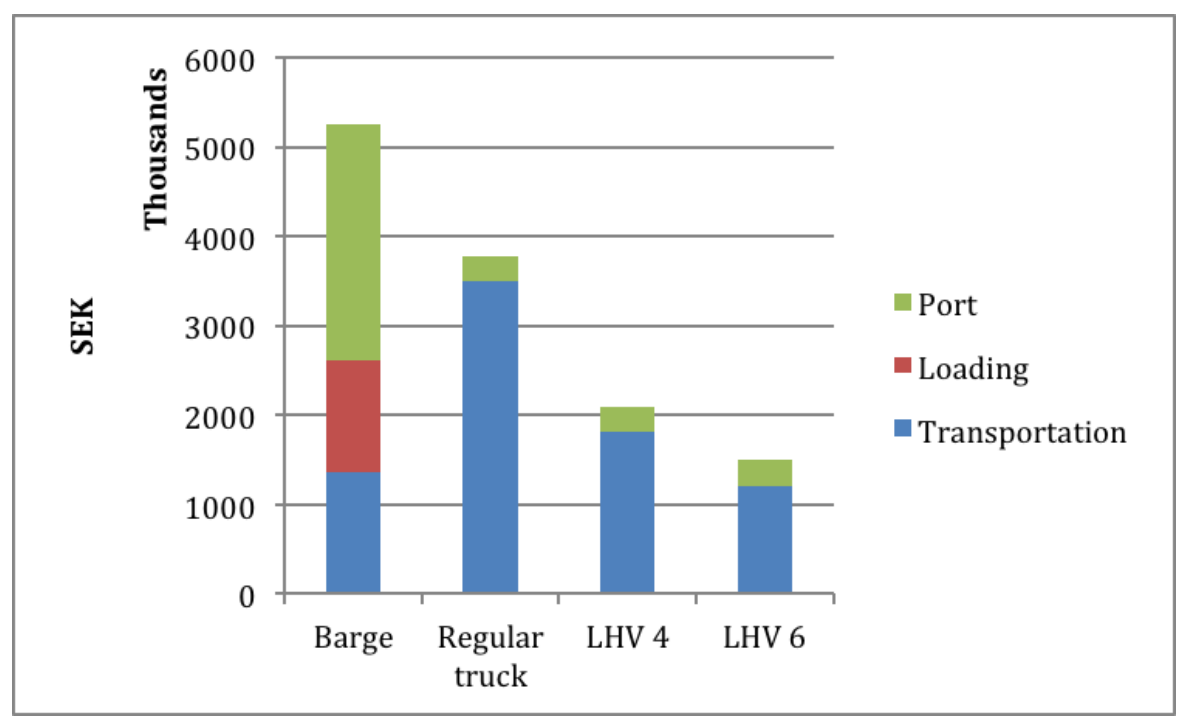

Figure 3 The Annual Cost with Different Transport Modes

performance that causes an annual external cost of $6701 €$

There is a gap between the results from the study and the studied literature. It is commonly stated in the literature that inland waterway transportation with barge provides a good transport economy in relation to road transportation. However, calculations for this case were not in favour of the barge mostly due to very high port charges as well as high container handling cost due to extra transhipment needed. Furthermore, relatively low container volumes for this route and the distance are contributing to barge not being viable. If the formerly mentioned handling costs could be reduced, the barge line would be more competitive compared to the regular truck and LHV.

\subsection{Environment}

The results from NTM calculations (Figure 4) show that the barge scenario has the worst environmental
The barge suffers high costs because of the relatively large amount of fuel consumed during transportation and mooring together with the fact that the fuel used is more polluting than the fuel for the trucks. This, together with two extra transhipments, i.e. more handling in the terminal area, which adds more external costs, approximately $40 \%$, are the main reasons for the high external costs for the barge scenario. The literature in many cases claims that inland waterway transportation with barges requires a certain critical distance to be environmentally efficient (Brnjac and Cavar, 2009). Moreover, the relatively small container volume affects the efficiency of the barge scenario. The LHV scenario is performing environmentally well due to the possibility to use less transport occasions for the same amount of containers. The trucks in this scenario also have a more modern Euro-class with more restrictions of the emissions. 


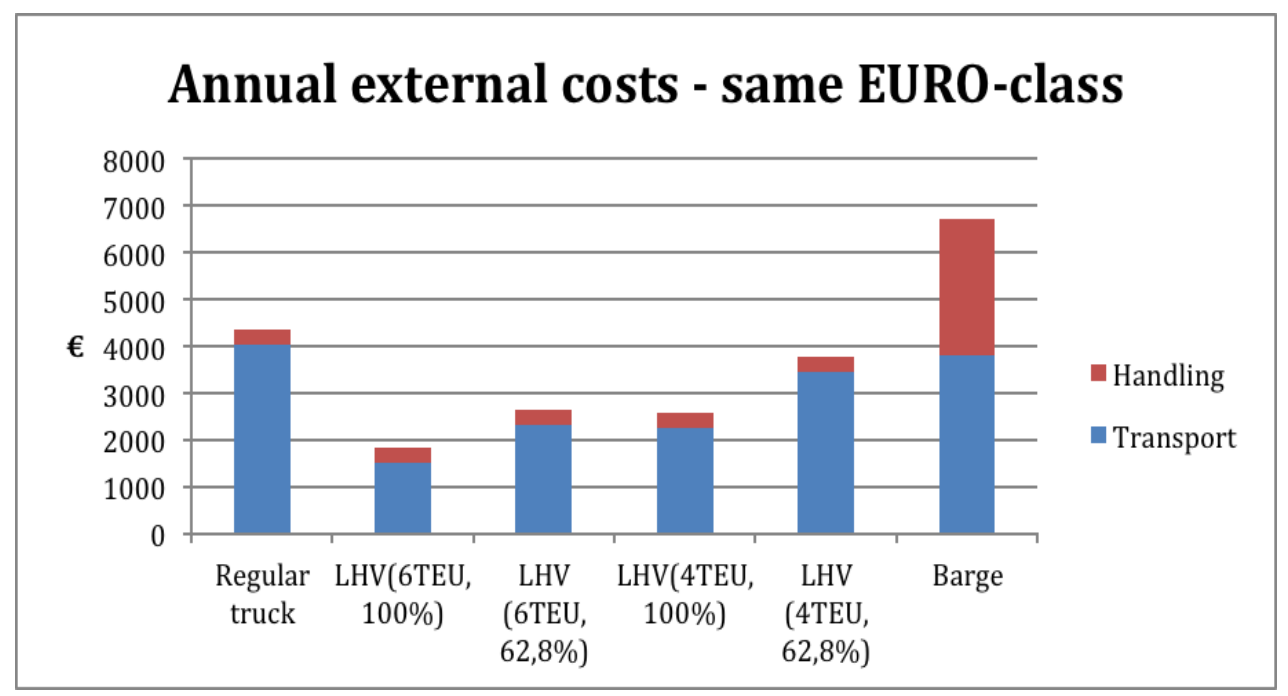

Figure 4 Annual External Costs for the Different Transportation Options

Environmental performances of the different transportation scenarios to the impact on the Natura 2000 area are evaluated in more of a qualitative manner. Since the Natura 2000 area has responsibilities for maintaining the environment and habitat for certain animals an assumption could be made that the less traffic on the roads the more beneficial for the Natura 2000 area. This could argue for the barge scenario since the traffic on the roads will become less dense. Also, the specific emissions from the different scenarios could pose different threats for the animal life in the area. The emissions causing environmental consequences on a more local or regional scale, rather than global, are probably more likely to harm the animals. These emissions are SOx, NOx and PM, which are extra obvious in the barge solution (all of the emissions) and the reference scenario (NOx and PM). The noise factor could nevertheless speak in favour of a barge line. This is because of the reduced noise of the engine, the less transport occasions and the location of the barge terminals that is far from the Nature 2000 area. Additionally, since some of the emissions related to the barge line are emitted at the container terminals, the Natura 2000 area is not equally exposed here.

Future aspects of the environmental performances of the different transportation scenarios are also of interest when performing the analysis. This is because the shipping business environment may change; hence the ratio between the scenarios may change as well. If empty containers volumes increase, the barge scenario may be the most beneficial one due to scale benefits.

\subsection{Flexibility}

The flexibility of regular truck transportation on this route is slightly superior to the LHV scenario. For the LHV transportation to be justified a certain capacity utilisation needs to be fulfilled, otherwise the regular truck transportation may as well continue to operate. If the demand for a container transport is smaller than the capacity of the LHV then there is a greater need for coordination of shipments to be able to consolidate containers or even postpone the shipment until a certain capacity utilisation is possible, hence the flexibility of delivery could be worsen. Nevertheless, the flexibility of the truck transportation in general is superior to the flexibility of the barge transportation. The range and the response measurements are both stronger due to the adaptability of the truck transportation. The trucks could depart and arrive at one of the nodes several times per day and the barge is much more limited in the number departures, due to economic reasons, therefore trucks are more adaptable to fluctuations in demand.

\subsection{Time Efficiency}

The total time for transportation, the link and the node time, of containers from Risholmen to the container terminal with both regular truck and LHV with four TEUs take equally long time according to the interviewed truck drivers who have driven the distances with both types of vehicles. This seems reasonable since the distances the two modes cover are almost similar. However, one-way transportation with one container between the sites takes usually about $1 \mathrm{~h}$ but could in worst case take up to $2 \mathrm{~h}$ and in a case of a smooth flow without the queues about $1 / 2 \mathrm{~h}$. LHV with six TEUs has not been in use but its transportation time should be equal as with regular truck, however not the handling time. The barge scenario should take approximately around $40 \mathrm{~min}$ in a normal one-way transportation. The best-case scenario could probably, if all steps run smooth, end up to be few minutes faster compared to the normal case. A worstcase scenario is hard to estimate and dependent on for example how occupied cranes, quays and the machinery at the terminal are; the likelihood that delays occur when using barge could therefore be greater.

The time efficiency criteria weigh in favour of the barge when comparing an average movement of only one container in one direction. However, when comparing the transportation time for a daily flow of containers in one direction, 40 TEUs, the result are not favourable due to long terminal handling time. The total time for 40 TEUs when using barge is calculated to approximately $5 \mathrm{~h}$ in a normal case scenario and $4,5 \mathrm{~h}$ in a very optimistic scenario. If several trucks would carry out the transportation of a daily demand of TEUs, the total transportation time is difficult to estimate and also very dependent on at which time period during the day the containers are transported. There are for 
example usually long queues for trucks around $4 \mathrm{pm}$ at the container terminal. Hence, it is hard to bring a conclusion regarding which of the modes that can be most time efficient when transporting 40 TEUs in one direction since there are too many uncertainties affecting the result.

\section{CONCLUSION}

The purpose with this study was to compare movement of empty containers by barge and LHV to the reference situation done by regular trucks, on the case of port of Gothenburg and one of its nearby depots; with regard to economy, environment, flexibility and time efficiency. According to the findings the most suitable mode of transport with respect to suggested criteria is LHV with a capacity of 6 TEUs. This conclusion is mainly based on the fact that LHV should perform better than regular trucks and/or a barge with respect to economy as well as environment, which were the most important criteria. However, the regular truck is performing equally or slightly better than LHV followed by barge regarding flexibility. Barge is superior with respect to the safety due to its good records, according to the literature. When it comes to time efficiency, it was hard to make a valid conclusion since the time needed for the different transportation modes when transporting daily demand of containers was difficult to estimate due to many potential interruptions. Nevertheless, the time criteria is of rather low importance since it was a question of minutes or in the worst case one hour for the units that are not urgently needed by shippers. This study showed importance of efficient and economically viable terminal handling since calculations for this case were not in favour of the barge mostly due to very high port charges as well as high container handling cost due to extra transhipment needed. Therefore, future research on how loading and unloading of containers on the terminals can be carried out more efficiently as well as research about strategies for increasing fill rates would be of interest.

\section{ACKNOWLEDGEMENTS}

This paper is based on an excerpt of the study presented in awarded master thesis by Andersson N. and Widstrand J. (2012) Evaluation of empty container transportation and opportunities for improvement; presented at Chalmers University of Technology, Division of logistics and transportation.

\section{REFERENCES}

Åkerman, I. \& Jonsson, R. (2007). European Modular System for Road Freight Transport - experiences and possibilities. KTH Department of Transportation and urban economics, Stockholm. Alderton, P. (2008) Port Management and Operations, Third edition, Informa Law, London.
Bardi, E., Coyle, J. \& Novack, R. (2006) Management of Transportation, Thomson South- Western.

Berwick, M. \& Dooley, F. (1997) Truck costs for owner/operators, Report Department of Transportation, University Transportation Centers Program, North Dakota State University.

Björklund, M. \& Paulsson, U. (2007) Seminarieboken - att skriva presentera och opponera. Lund: Studentlitteratur.

Brnjac, N. \& Cavar I. (2009) Example of positioning intermodal terminals on inland waterways. Promet Traffic\&Transportation 21(6), pp. 433-439.

European Environmental Agency (2009) Transport at a crossroads- TERM 2008: Indicators tracking transport and environment in the European Union, European Environmental Agency, Copenhagen

Flyvbjerg, B., 2006. Five misunderstandings about case-study research. Qual. J. 12 (2), pp. 219-245.

Gunnmalm, L. (2009) Trafik Hjärtholmsvägen. Consultancy Report. Göteborgs hamn.

Konings, R. (2003) Network design for intermodal barge transport, Delft University of Technology.

Konings, R. (2007) Opportunities to improve container barge handling in the port of Rotterdam from transport network perspective, Journal of Transport Geography 15(6), pp. 443454

Lowe, D. (2005) Intermodal Freight Transport, ButterworthHeinemann Ltd.

McKinnon, A.C. (2005) The economic and environmental benefits of increasing maximum truck weight: The British experience, Transportation Research Part D 10(1), pp.77-95.

Naturvårdsverket (2012) Natura 2000. http://www.naturvardsverket.se/natura2000 (Retrieved:201203-14).

NTM (2007) Methods and data for environmental assessment of international cargo transport, Swedish Environmental Research Institute (IVL) Gothenburg, Sweden.

Port of Gothenburg (2013). Rail Services, Annual Report, Gothenburg.

Rakic, B. \& Stegeman, J., (2011) Monitoring Traffic Safety and Heavier vehicles. Rijkswaterstaat Ministry of Infrastructure and the Environment.

Roso, V., Lumsden K., Kjell, M. \& Westerlund, K. (2009a) Longer combination vehicles- solution to sustainable pre and posthaulage in Sweden? Proceedings of 12th World Conference on Transport Research, Lisbon, Portugal.

Roso, V., Woxenius, J.; Lumsden, K. (2009b) The dry port concept: connecting container seaports with the hinterland, Journal of Transport Geography 17(6), pp. 338-345.

Song, D.P. \& Carter, J. (2009) Empty container repositioning in liner shipping. Maritime Policy \& Management: The flagship journal of international shipping and port research 36(4), pp. 291-307

Wiegmans, B. \& Konings, R. (2007) Strategies and innovations to improve the performance of barge transport, European Journal of Transport and Infrastructure Research 7(2), pp. 145-162

Violeta Roso is an Associate Professor at division of Logistics and Transportation, Chalmers University of Technology, Sweden; where she obtained her PhD Degree in Technology Management and Economics. She has been researching on intermodal transport and dry ports and has written numerous highly cited research papers published in international scientific journals, such as Transportation Research, Journal of Transport Geography, IJPDLM, WRITR, Maritime Economics and Logistics and UNESCAP Transport Bulletin.

Nils Andersson and Joakim Widstrand obtained their Master of Science degree at International Master Program Supply Chain Management, at Chalmers University of Technology, Sweden. 
Kent Lumsden is a full time professor in Transportation and Logistics at Chalmers University of Technology. He has worked as an EU Expert/Evaluator for DGVII, was involved in start-up of a number of Swedish academic programmes related to transport economics, transport technology and logistics. He has written textbooks on logistics and been principal/co-author of more than 50 conference, journal and research papers. 